\title{
The effect of age, sex, obesity and posture on upper airway size
}

\author{
S.E. Martin*, R. Mathur*, I. Marshall**, N.J. Douglas*
}

The effect of age, sex, obesity and posture on upper airway size. S.E. Martin, R. Mathur, I. Marshall, N.J. Douglas. CERS Journals Ltd 1997.

ABSTRACT: Most patients with sleep apnoea/hypopnoea syndrome (SAHS) are middle-aged men. As there are conflicting data on the effects of age and gender on upper airway calibre, we tested the hypothesis that increasing age and the male sex predispose to upper airway narrowing in normal subjects.

We measured upper airway calibre using acoustic reflection in 60 men and 54 women (median 35, range 16-74 yrs) both seated and supine.

All upper airway dimensions, except oropharyngeal junction (OPJ), decreased with increasing age in both men and women $(r>-0.24, p \leq 0.05)$ while supine $\left(r^{2}>0.06\right)$. Men had greater changes in airway area at OPJ on lying down (mean (SEM) $\left.0.5(0.1), 0.2(0.1) \mathrm{cm}^{2} ; \mathbf{p}<0.02\right)$. Men had greater body mass indices (mean

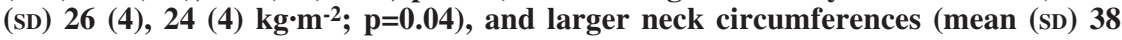
(3), 33 (2) $\mathrm{cm} ; \mathbf{p}<0.0001)$ than women. For any body mass index, neck circumference was larger in men than women $(\mathbf{p}<0.001)$.

This study shows that upper airway size decreases with increasing age in both men and women, and that men have greater upper airway collapsibility on lying down at oropharyngeal junction than women.

Eur Respir J 1997; 10: 2087-2090.

\author{
* Respiratory Medicine Unit, Dept of \\ Medicine, and **Dept of Medical Physics, \\ The University of Edinburgh, Edinburgh, \\ UK. \\ Correspondence: N.J. Douglas \\ Respiratory Medicine Unit \\ Dept of Medicine \\ The University of Edinburgh \\ Royal Infirmary \\ Lauriston Place \\ Edinburgh EH3 9YW \\ UK \\ Keywords: Age \\ obesity \\ upper airway
}

Received: October 211996

Accepted after revision May 121997

This study was supported by the Scottish Home Office and Health Dept.
The effects of age and gender on upper airway calibre are unclear. Clarification of their influences is important because the clinical condition associated with upper airway narrowing, the sleep apnoea/hypopnoea syndrome (SAHS), is predominantly a condition of middle-aged men [1]. Brooks and Strohl [2] reported men to have larger upper airway calibre than women when seated and awake. Studies performed in the sitting position have indicated that upper airways resistance increases, and pharyngeal area decreases [3] with age in men but not in women. In contrast, computed tomography (CT) scan studies in supine men have shown no age-related increase in upper airway collapsibility in men [4]. In order to clarify this, we tested the hypothesis that increasing age and the male sex predispose to upper airway narrowing in the normal population.

\section{Methods}

\section{Subjects}

We aimed to select a cross section of the local population and therefore recruited 60 male and 54 female subjects from the hospital workforce using an advertisement that did not refer to sleep. Their height, weight and neck circumference at the cricothyroid membrane were measured (table 1). Subjects were asked whether they snored and in which position, and whether they suffered from uncontrollable daytime sleepiness. Responses were noted but no one was excluded from the analysis as this was a population-based study. However, subjects with gross retrognathia were assessed clinically and excluded from the analysis. The study was approved by the local Ethics Advisory Committee.

\section{Measurements}

Upper airway dimensions were measured using the acoustic reflection technique [5, 6], modified as we have reported previously [7]. The accuracy of acoustic reflection devices was validated using both in vitro models and in vivo comparison with magnetic resonance imaging (MRI) when area measurements were found to be within $10 \%$ [7]. We have used a scuba diving type mouthpiece for all of our studies, including the MRI validation study. In common with other studies [8-11], we

Table 1. - Anthropometric data for the study sample

\begin{tabular}{lll}
\hline & Males & Females \\
\hline Subjects n & 60 & 54 \\
Age yrs & $40(15)$ & $45(16)$ \\
BMI kg.m-2 & $26(4)$ & $24\left(^{+}\right.$ \\
Neck cm & $38(3)$ & $33(2)^{\#}$ \\
Snorers & & \\
$\quad$ Total & 28 & 21 \\
Back only & 19 & 14 \\
$\quad$ All positions & 9 & 7 \\
Daytime sleepiness & 5 & 4 \\
\hline
\end{tabular}

Values are presented as means, with SD in parentheses. BMI: body mass index; Neck: neck circumference. ${ }^{+}: \mathrm{p}=0.04$; \#: $\mathrm{p}<0.0001$. 
have found that these mouthpieces have been easy to use and that they produce reproducible measurements $[8,11]$. Our within-run coefficient of variation for upper airway areas in human volunteers is $10 \%$ [7], similar to that found by Brooks et al. [8].

\section{Protocol}

Subjects breathed from a mouthpiece attached to the acoustic reflection system. They were asked to breathe through the mouth with no noseclip, so as to keep the nasopharynx occluded by the palate, preventing the loss of soundwaves into the nasal cavity. Ten measurements of the upper airway were taken at the beginning of inspiration (i.e. zero flow), sitting upright and lying down (supine position). Cross sectional area versus distance down the airway traces was then reconstructed on the computer screen and the means of technically acceptable traces were taken.

Traces were screened for having a standard curve of mouth peak, oropharyngeal minimum, pharyngeal peak and glottis minimum (fig. 1). Nasal breathing was identified by the total loss of the pharyngeal peak (oropharyngeal junction (OPJ) to glottis). Mixed (oral/nasal) breathing was identified by up to $2 \mathrm{~cm}^{2}$ increases in any of the mouth, pharyngeal or glottic airway areas. If there was uncertainty about the route of breathing during measurements, we repeated the instructions to the subject and repeated measurements until satisfied that we had made measurements while the subject was mouth breathing.

Five upper airway measurements were read off the mean trace (fig. 1): oropharyngeal junction $\left(\mathrm{cm}^{2}\right)$; maximum pharyngeal area $\left(A \mathrm{p}, \max ; \mathrm{cm}^{2}\right)$; glottis $\left(\mathrm{cm}^{2}\right)$; mean cross sectional area from the OPJ to the glottis $(A \mathrm{p}$,mean; $\left.\mathrm{cm}^{2}\right)$; and pharyngeal volume $\left(V \mathrm{p} ; \mathrm{cm}^{3}\right)$ as the integrated area under the curve between the OPJ and the glottis. These measurements were selected as they cover a range of anatomical points of interest in the upper airway. OPJ (the junction between the soft palate and the oropharynx) and $A$ p,max (the maximum area in the hypopharynx) are of interest as sites of upper airway collapse in patients with sleep apnoea [12-14]. Glottic area, $A \mathrm{p}$,mean and $V_{\mathrm{p}}$ have been used in other studies [8, 15] and are essential measurements as points of reference in this study.



Fig. 1. - Sample trace of upper airway area versus distance down the upper airway. OPJ: orophrayngeal junction; $A$ p,max: maximum pha-

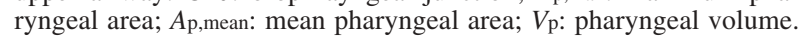

Table 2. - Upper airway dimensions in men and women in both seated and supine positions

\begin{tabular}{|c|c|c|c|c|}
\hline & \multicolumn{2}{|c|}{ Men } & \multicolumn{2}{|c|}{ Women } \\
\hline & Seated & Supine & Seated & Supine \\
\hline OPJ $\mathrm{cm}^{2}$ & $1.8(0.1)^{* *}$ & $1.3(0.1)$ & $1.6(0.1)$ & $1.3(0.1)$ \\
\hline$A \mathrm{p}, \max \mathrm{cm}^{2}$ & $2.8(0.1)^{* *}$ & $2.2(0.1)$ & $2.5(0.1)$ & $2.1(0.1)$ \\
\hline Glottis $\mathrm{cm}^{2}$ & $1.7(0.1)$ & $1.7(0.1)$ & $1.8(0.1)$ & $1.7(0.1)$ \\
\hline$A \mathrm{p}$, mean $\mathrm{cm}^{2}$ & $2.2(0.1)^{*}$ & $1.8(0.1)$ & $2.1(0.1)$ & $1.7(0.1)$ \\
\hline$V \mathrm{p} \mathrm{cm}^{3}$ & $19.6(0.9)$ & $15.9(0.7)$ & $17.8(0.7)$ & $14.8(0.6)$ \\
\hline
\end{tabular}

Values are presented as means with SEM in parentheses. *: $\mathrm{p}<0.05$; **: $\mathrm{p}<0.01$, significant differences between men and women. For definitions, see legend to figure 1.

\section{Statistical analysis}

We analysed our data using two-way analysis of variance with posture as a within-subjects factor and sex as a between-subjects factor, unpaired t-test, and bivariate and partial Pearson correlation coefficients. A p-value of less than 0.05 was considered significant.

\section{Results}

When seated, men had larger upper airway areas at OPJ $(\mathrm{p}<0.01), A \mathrm{p}$, max $(\mathrm{p}<0.01)$, and $A \mathrm{p}$, mean $(\mathrm{p}<0.03)$ than women. There were no significant differences between the sexes in supine airway areas or volumes (table 2).

\section{Effect of age}

In both men and women in the supine posture, $A \mathrm{p}$,max, glottis, $V_{\mathrm{p}}$ and $A \mathrm{p}$,mean decreased with increasing age (table 3 ). In seated men, upper airway calibre decreased with increasing age at $V_{\mathrm{p}}$ and $A \mathrm{p}$,mean only. In seated women, only $V_{\mathrm{p}}$ decreased with increasing age. Age explained $6-13 \%$ of the variance in upper airway dimensions in seated or supine men, and 6-11\% in women in either position.

Table 3. - Pearson correlation coefficients of relationships between age, BMI and neck circumference, and upper airway dimensions in men and women

\begin{tabular}{|c|c|c|c|c|c|c|}
\hline & \multicolumn{2}{|r|}{ Age } & \multicolumn{2}{|c|}{ BMI } & \multicolumn{2}{|c|}{ Neck } \\
\hline & Men & Women & Men & Women & Men & Women \\
\hline Age & - & - & - & - & - & - \\
\hline BMI & 0.36 & 0.25 & - & - & - & - \\
\hline Neck & 0.30 & 0.16 & 0.83 & 0.76 & - & - \\
\hline \multicolumn{7}{|c|}{$\begin{array}{l}\text { Upper airway; seated } \\
\text { OPJ }\end{array}$} \\
\hline$A \mathrm{p}, \max$ & & & & -0.30 & & -0.24 \\
\hline Glottis & & & & & & -0.31 \\
\hline$A \mathrm{p}$, mean & -0.25 & & -0.25 & -0.28 & & -0.26 \\
\hline$V \mathrm{p}$ & -0.29 & -0.24 & & -0.30 & & -0.26 \\
\hline \multicolumn{7}{|c|}{ Upper airway; supine } \\
\hline OPJ & & & & & & 0.28 \\
\hline$A \mathrm{p}, \max$ & -0.34 & -0.28 & & & & \\
\hline Glottis & -0.37 & -0.34 & & & & \\
\hline$A \mathrm{p}$, mean & -0.30 & -0.24 & & & & \\
\hline$V_{\mathrm{p}}$ & -0.34 & -0.32 & & & -0.25 & \\
\hline
\end{tabular}

For simplicity, correlation coefficients are shown only when significant. Men: $r>0.23 p<0.05, r>0.30 p<0.01, r>0.43 p<0.001$. Women: $r>0.24 \mathrm{p}<0.05, \mathrm{r}>0.31 \mathrm{p}<0.01, \mathrm{r}>0.44 \mathrm{p}<0.001$. Neck: neck circumference; BMI: body mass index. For further definitions, see legend to figure 1 . 
Women were subdivided into two groups according to menopausal status $(n=31$ premenopausal, and $n=23$ postmenopausal). There were no significant differences between pre- and postmenopausal women in upper airway calibre (all p>0.3). There were no differences in body mass index $(\mathrm{BMI})(\mathrm{p}=0.5)$ or neck circumference $(\mathrm{p}=0.5)$ with menopausal status.

\section{Obesity}

In men, there were significant relationships between BMI and $A \mathrm{p}$,mean when seated $(\mathrm{r}=-0.25, \mathrm{p}<0.05)$. In women, there were significant relationships between BMI and $A$ p,mean, $A$ p, max and $V_{\mathrm{p}}$ when seated (all $\mathrm{r}<-$ $0.28, \mathrm{p}<0.05$; table 3 ).

\section{Neck circumference}

Neck circumference correlated significantly with BMI in both men $(\mathrm{p}<0.001)$ and women $(\mathrm{p}<0.001$; fig. 2$)$. However, these relationships were significantly different between the sexes at similar BMI $(\mathrm{p}<0.001)$, exemplified by the small amount of overlap seen in their respective values (fig. 2; range 33-45 cm, men; 30-39 $\mathrm{cm}$, women). Neck circumference correlated with age in men $(r=0.31, p<0.04)$ but not in women $(r=0.16, p>0.2)$. Upon controlling for BMI, using partial correlation coefficient analysis, the relationship between neck circumference and age in men was not significant. In women, increasing neck circumference correlated significantly with decreasing upper airway calibre at $A$ p,max, glottis, $V \mathrm{p}$ and $A$ p,mean $($ all $\mathrm{r}<-0.24, \mathrm{p}<0.05)$ in the seated position. However, in the supine position, increased neck circumference correlated significantly with increased upper airway calibre at OPJ in women $(\mathrm{r}=0.28, \mathrm{p}<0.03)$ but not in men $(\mathrm{r}=0.01, \mathrm{p}=0.5)$. In men, increasing neck circumference correlated significantly with decreasing $V_{\mathrm{p}}$ in the supine position $(\mathrm{r}=0.25, \mathrm{p}=0.04)$.

\section{Effects of age, obesity and neck size}

As age was positively correlated with obesity and neck size, partial correlation analysis of their effects on airway calibre was performed. The relationship between age and supine airway calibre remained significant when obesity and neck size were included both in men

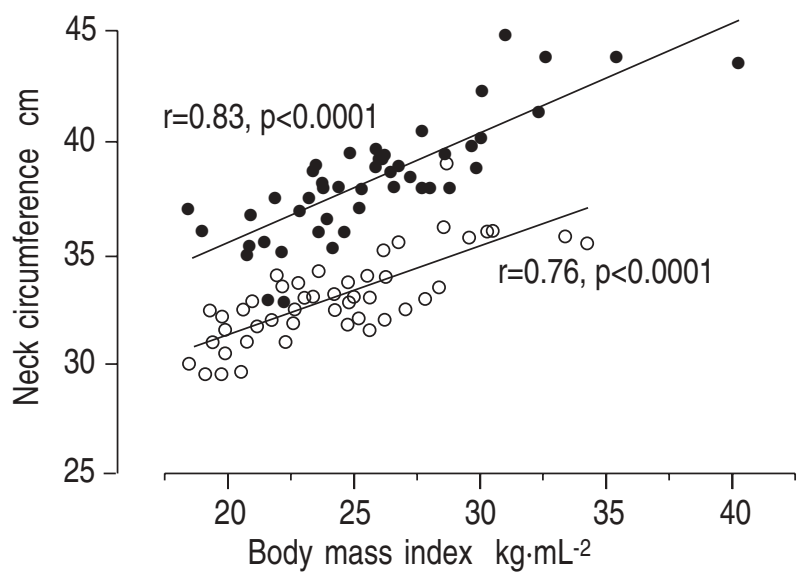

Fig. 2. - Relationships between body mass index and neck circumference for men $(\bullet)$ and women $(\circ)$.
$\left(A \mathrm{p}\right.$,mean, $V_{\mathrm{p}}, A \mathrm{p}, \max$ and glottis; all $\left.\mathrm{p}<0.04\right)$ and women $(V \mathrm{p}$, glottis; $\mathrm{p}<0.02)$. There was also a significant independent effect of age on $V p$ in seated men $(p<0.05)$.

\section{Effect of posture}

Men had significantly greater changes in upper airway area at the OPJ on lying down than women (mean (SEM) $0.5(0.1) \mathrm{cm}^{2}$ male, $0.2(0.1) \mathrm{cm}^{2}$ female; $\left.\mathrm{p}<0.02\right)$, with a trend towards men having a significantly greater change in upper airway area at $A$ p, max $\left(0.6(0.1) \mathrm{cm}^{2}\right.$ male, $0.3(0.1) \mathrm{cm}^{2}$ female; $\left.\mathrm{p}<0.07\right)$ on lying down. We found no significant difference between men and women in the effect of posture on glottic area $(p>0.5), A p$,mean $(\mathrm{p}=0.1)$ or $V_{\mathrm{p}}(\mathrm{p}>0.6)$. There was no significant relationship between BMI and change in upper airway area on lying down in men, but the change in $V_{\mathrm{p}}$ on lying was correlated with BMI in women $(\mathrm{r}=-0.27, \mathrm{p}=0.05)$.

\section{Less obese subjects}

As the women had lower BMIs than the men $(\mathrm{p}=0.04)$, we examined the data for all subjects with BMIs $\leq 26$ $\mathrm{kg} \cdot \mathrm{m}^{-2}$ to factor out major effects of obesity. Twenty men and 10 women with $\mathrm{BMI}>26 \mathrm{~kg} \cdot \mathrm{m}^{-2}$ were excluded. The remaining 40 men and 44 women had similar BMIs but were significantly different in age (mean (SD) 36 (14) male, 45 (16) female; $p<0.02$ ). These men had a significantly greater change in OPJ area on lying down than women $(\mathrm{p}<0.02)$, and tended to have greater changes in upper airway calibre at $A \mathrm{p}, \max (\mathrm{p}<0.06)$ and $A \mathrm{p}$,mean $(\mathrm{p}=0.09)$ on lying down.

\section{Discussion}

This study confirms [15] that men have larger upper airways than women when seated and that upper airway calibre decreases in men with increasing age $[3,16]$. However, in contrast to an earlier study [3], we have demonstrated that upper airway calibre decreases with increasing age in women as well as men. These changes in upper airway calibre may help explain why the frequency of irregular breathing during sleep increases with age, both in men and in women [1].

The results demonstrating that upper airway dimensions decrease with age in women are in contrast to those of White et al. [3]. They only measured upper airway calibre while seated, which may account for the differences between these studies as we found that the decrease in upper airway calibre with age was detected only in the supine posture. This might suggest an effect of ageing on the defence of the upper airway calibre, with impaired upper airway dilating muscle activity with age, but this remains to be examined.

Men were found to have larger decreases in upper airway area at the OPJ than women on lying down. This is compatible with the observation of POPOVIC and WHITE [17] that women have greater genioglossal muscle tone than men, suggesting greater defence of their upper airway. Furthermore, our observation that women have larger supine upper airway areas at the OPJ with increasing neck circumference also suggests that women are more capable of defending their upper airways in response to mass loading. There was an almost complete lack of relationships between upper airway size and neck 
circumference in men in this study. This is different to the finding of RYAN and Love [18] that velopharyngeal compliance in patients with sleep apnoea correlates significantly with neck circumference. Relationships between neck circumference and upper airway calibre are multifactorial depending on facial structure, fat deposition and upper airway muscle function, all of which are altered in SAHS patients. Therefore, it is not surprising that we did not find any relationships between neck circumference and upper airway calibre in men in this study.

It is difficult to extrapolate the observations on upper airway calibre made in the current study to the pathogenesis of sleep apnoea for several reasons. Firstly, the acoustic reflection technique does not examine the nasopharynx which is a common site of upper airway occlusion. However, most patients occlude their upper airway during sleep over a significant length $[12,14]$ and the oropharynx is occluded during obstructive events in most patients. Against this potential disadvantage of acoustic reflection, has to be set the advantage that it can be used to examine the effects of posture on the upper airway whereas other noninvasive techniques such as MRI and CT scanning can only be performed supine. A second disadvantage of the current study is that it was performed in awake subjects and the results cannot, therefore, be safely extrapolated to sleep. Thirdly, the studies were performed in subjects from a normal population and it would not be safe to extrapolate our findings to the causation of sleep apnoea.

We have found a highly significant difference in neck circumference between men and women at the same BMIs. Adipose tissue has different distributions in men and women [19]. Men generally tend to deposit adipose tissue around the trunk and abdomen, whereas women show deposition around the periphery: upper arms, hips and thighs. Similar increased fat deposition in the neck may explain why, in our sample, men had larger neck circumferences than women at similar BMIs. Such fat deposition has been associated with the development of SAHS [20-22]. It is noteworthy that the differences in neck circumference between the sexes were similar at all body masses and that it was not merely that obese men had larger necks while thin men and women had similar neck sizes. It is thus possible that increased muscle bulk could also contribute to the differences in neck size.

There were statistically significant correlations between various indices of upper airway calibre and age, body mass and neck size (table 3). However, none of these correlations on their own explained more than $13 \%$ of the variance in airway calibre, and thus their importance must not be overstated. This study shows that upper airway calibre decreases with increasing age in both men and women. The causes of this age-related change remain to be elucidated.

\section{References}

1. Young T, Palta M, Dempsey J, Skatrud J, Webber S, Bade S. The occurrence of sleep disordered breathing among middle aged adults. $N$ Engl J Med 1993; 328: 1230-1235.

2. Brooks LJ, Strohl KP. Size and mechanical properties of the pharynx in healthy men and women. Am Rev Respir Dis 1992; 146: 1394-1397.

3. White DP, Lombard RM, Cadieux RJ, Zwillich CW. Pharyngeal resistance in normal humans: influence of gender, age and obesity. Appl Physiol 1985; 58: 365371.

4. Burger CD, Stanson AW, Sheedy PF, Daniels BK, Shepard JW Jr. Fast-computed tomography evaluation of agerelated changes in upper airway structure and function in normal men. Am Rev Respir Dis 1992; 145: 846-852.

5. Fredberg JJ, Wohl MB, Glass GM, Dirkin HL. Airway area by acoustic reflections measured at the mouth. $J$ Appl Physiol 1980; 48: 749-758.

6. Jackson AC, Butler JP, Millet EJ, Hopin FG Jr, Dawson SV. Airway geometry by analysis of acoustic pulse response measurements. J Appl Physiol 1977; 43: 523-536.

7. Marshall I, Maran NJ, Martin S, et al. Acoustic reflectometry for airway measurements in man: implementation and validation. Physiol Meas 1994; 14: 157-169.

8. Brooks LJ, Byard PJ, Fouke JM, Strohl KP. Reproducibility of measurements of upper airway area by acoustic reflection. J Appl Physiol 1989; 66: 2901-2905.

9. Jan MA, Marshall I, Douglas NJ. Effect of posture on upper airway dimensions in normal human. Am J Respir Crit Care Med 1994; 149: 145-148.

10. Martin SE, Marshall I, Douglas NJ. The effect of posture on airway calibre in patients with the sleep apnoea/ hypopnoea syndrome. Am J Respir Crit Care Med 1995; 152: 721-724.

11. Rubinstein I, McClean PA, Boucher R, Zamel N, Fredberg JJ, Hoffstein V. Effect of mouthpiece, noseclips, and head position on airway area measured by acoustic reflections. J Appl Physiol 1987; 63: 1469-1474.

12. Chaban R, Cole P, Hoffstein V. Site of upper airway obstruction in patients with idiopathic obstructive sleep apnoea. Laryngoscope 1988; 98: 641-647.

13. Shepard JW Jr, Thawley SE. Localisation of upper airway collapse during sleep in patients with obstructive sleep apnoea. Am Rev Respir Dis 1990; 141: 1350-1355.

14. Hudgel DW. Variable site of airway narrowing among sleep apnoea patients. J Appl Physiol 1986; 61: 1403-1409.

15. Fouke JM, Strohl KP. Effect of position and lung volume on upper airway geometry. J Appl Physiol 1987; 63: 375-380.

16. Brown IB, Zamel N, Hoffstein V. Pharyngeal cross-sectional area in normal men and women. J Appl Physiol 1986; 61: 890-895.

17. Popovic RM, White DP. Gender differences in waking genioglossal EMG (GG-EMG) and pharyngeal resistance. Am J Respir Crit Care Med 1995; 152: 725-731.

18. Ryan CF, Love LL. Mechanical properties of the velopharynx in obese patients with obstructive sleep apnea. Am J Respir Crit Care Med 1996; 154: 806-812.

19. Edwards D. Differences in the distribution of subcutaneous fat with sex and maturity. Clin Sci 1951; 10: 305-315.

20. Horner RL, Mohiaddin RH, Lowell DG, et al. Sites and sizes of fat deposits around the pharynx in obese patients with obstructive sleep apnoea and weight matched controls. Eur Respir J 1989; 2: 613-622.

21. Katz I, Stradling J, Slutsky AS, Zamel N, Hoffstein V. Do patients with obstructive sleep apnoea have thick necks? Am Rev Respir Dis 1990; 141: 1228-1231.

22. Shelton KE, Woodson H, Gay S, Suratt PM. Pharyngeal fat in obstructive sleep apnoea. Am Rev Respir Dis 1993; 148: 462-466. 